\title{
Using medium-range ensemble inflow scenarios for decision support on the sediments management of a hydropower dam
}

\begin{abstract}
This short communication summarizes results of an investigation of the viability of using ensemble inflow forecasts to help the management of sediments in the reservoir of a hydroelectric dam in the Doce river, Brazil. To avoid sedimentation of the reservoir, sediment removal actions are required that depend on flow forecasts. The results suggest that using some of the predictions tested is almost equivalent to using rainfall in the region as the expected rainfall.
\end{abstract}

Keywords: ensemble forecasting, hydrological modeling, sediment management
Volume 2 Issue I - 2018

\author{
Fernando Mainardi Fan \\ Department of Hydraulic Research, Federal University of Rio \\ Grande do Sul, Brazil \\ Correspondence: Fernando Mainardi Fan, Department of \\ Hydraulic Research, Federal University of Rio Grande do Sul, \\ Brazil, Tel +55 5I-3308-64 I4, Fax +55 5I-3308-729I, \\ Email fernando.fan@ufrgs.br
}

Abbreviations: HPP, Hydro Power Plant; NWP, Numerical Weather Predictions; QPF, Quantitative Precipitation Forecasts; EPS, Ensemble Prediction Systems; ECMWF-pf, European Center for Medium-Range Weather Forecasts probabilistic forecast; GEFS, Global Ensemble Forecasting System; CPTEC-pf, Centro de Previsão de Tempo e Estudos Climáticos probabilistic forecast; ECMWF-fc, European Center for Medium-Range Weather Forecasts forecast

\section{Introduction}

Forecasts of hydrological variables at a medium-range horizon, from one to two weeks, are useful to operate reservoirs, especially if these are used for hydropower generation and are constrained due to multiple water uses. In the present study we investigate the use of medium-range scenarios of reservoirs inflow for a decision making procedure related to a reservoir operation in the Doce River basin, in Brazil. The main location of interest for hydrological forecasting in the Doce River basin is the reservoir of the Aimorés Hydro Power Plant (HPP). The drainage area of the HPP is approximately $63,000 \mathrm{~km}^{2}$. Aimorés HPP is owned by a consortium of CEMIG (Companhia Energética de Minas Gerais) and Vale (Mineradora Vale). It has an installed generation capacity of $330 \mathrm{MW}$, and its reservoir has a total volume of approximately 184.66 million cubic meters. During the daily operations this reservoir acts as a "trap" to the large amount of sediments that originates from the upstream basin of the Doce River. This motivates a cleaning process called "pass through" to periodically remove the sediments from the upstream area of the reservoir and avoid greater problems in terms of backwater flooding, hydropower generation and dam safety. The "pass through" or "sediments flushing" process consists of a decrease of the reservoir's water level to a certain flushing level when a determined reservoir inflow threshold is forecasted. Then, the water in the approaching inflow is used to flush the sediments from the reservoir through the spillway and to recover the original reservoir storage. To be triggered, the sediments flushing operation requires an inflow larger than $2500 \mathrm{~m}^{3} / \mathrm{s}$ in a forecast horizon of 7 days. This number of days is not only related to the reservoir volume, but also related to the time necessary to make all the preparations with the local authorities to authorize the procedures. The operation can only be aborted without major impacts within a 3 days lead time. A lead-time of 7 days is far beyond the basin's concentration time (around 2 days), meaning that the forecasts for the pass-through procedure highly depends on Numerical Weather Predictions (NWP) models that generate Quantitative Precipitation Forecasts (QPF). This dependency on medium-range NWP creates an environment with a high amount of uncertainty to the operators, since the meteorological uncertainty of the QPF is usually a key factor in medium-range hydrological forecasting. ${ }^{1}$ Fan et al. ${ }^{2}$ also studied ensemble forecasts in a broader study that included the Doce river region and showed that forecasts with lead times over 3 days have increasing errors. To support the decision making related to executing the flushing process at Aimorés HPP, we developed a fully operational hydrological forecasting system to the basin. The forecasting system can generate ensemble streamflow forecasts scenarios when driven by QPF data from meteorological Ensemble Prediction Systems (EPS). This approach allows accounting for uncertainties in the NWP at a decision-making level. This research has the objective of verifying what is the added value of the ensemble scenarios (in comparison to a deterministic reference) and what are the conditions to trigger the flushing process provided by the medium-range ensemble forecasts for this decision-making problem.

\section{Development}

The hydrological model used in the developed system was the MGB-IPH large-scale model ${ }^{3,4}$ and largely applied on Brazil. The model was calibrated and coupled to the Delft-FEWS software shell, presented by Werner et al. ${ }^{5}$ This system is starting to be used operationally by CEMIG and is the one used in the present study. The QPF data used in this study was derived from the TIGGE (THORPEX Interactive Grand Global Ensemble) database. This initiative is described by Bougeault et al. ${ }^{6}$ and consists of a database of mediumrange forecasts issued by different centers around the world, that stay available for conducting scientific research. Among all EPS available on TIGGE, three were selected: ECMWF-pf (European Center 
for Medium-Range Weather Forecasts), GEFS (Global Ensemble Forecasting System issued by NOAA), and CPTEC-pf (Centro de Previsão de Tempo e Estudos Climáticos global model, from Brazil). As a deterministic reference forecast, we adopt the high-resolution ECMWF-fc forecast for comparison. It is also available in the TIGGE database. Finally, an extra forecasting option is evaluated in the present study, and it consists in the use of all EPS products together, as a Grand Ensemble. The experiment consisted on running retrospective forecasts (hindcasting) from July 2007 to July 2012, a full five-year period, of the Aimorés HPP inflow. To verify the proposed objectives of the study, we use different metrics to evaluate the forecasts skill (described by): ${ }^{7}$ Brier Score, ROC Curves and Reliability Diagrams. Figure 1 shows the study flowchart. Figures $2-4$ presents the metrics results obtained in the study. The threshold used in the analysis was $2500 \mathrm{~m}^{3} / \mathrm{s}$. Metrics results enabled to understand the benefits of the hydrological ensemble prediction system as a decision-making tool for the HPP operation. Brier scores indicated that, for the detection of the $2500 \mathrm{~m}^{3} / \mathrm{s}$ threshold, results from the grand ensemble, ECMWF ensemble, and GEFS ensemble are almost as good as using perfect forecasts (i.e. observations as future rainfall). The ROC scores indicate that the use of the lower percentiles of the ensemble scenarios issues for a true alarm rate around 0.5 to 0.8 (depending on the model and on the percentile), for the lead time of seven days. While the false alarm rate is between 0 and 0.3 .

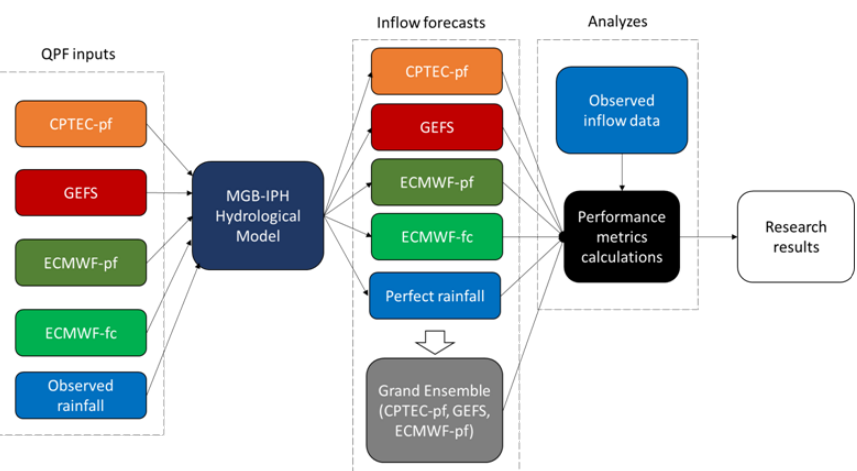

Figure I Study flowchart.

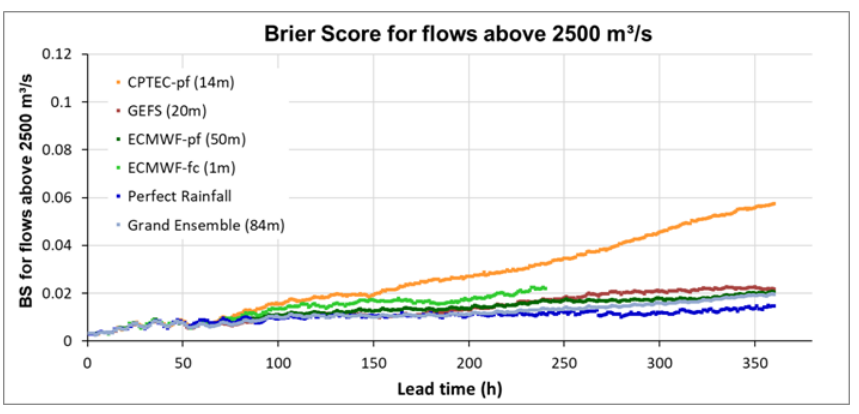

Figure 2 Brier Score (BS) results for flows above $2500 \mathrm{~m}^{3} / \mathrm{s}$.

Finally, reliability diagrams show that the calibration of ECMWF ensemble and GEFS ensemble forecasts is good for 120 hours (5 days) and 240 hours (10 days) lead times, but loses quality for greater lead-times. The comparison between the EPS also showed differences in the meteorological model's performances, and the composition of the Grand Ensemble suggests that its performance is usually equal or better than the results obtained using one single EPS.
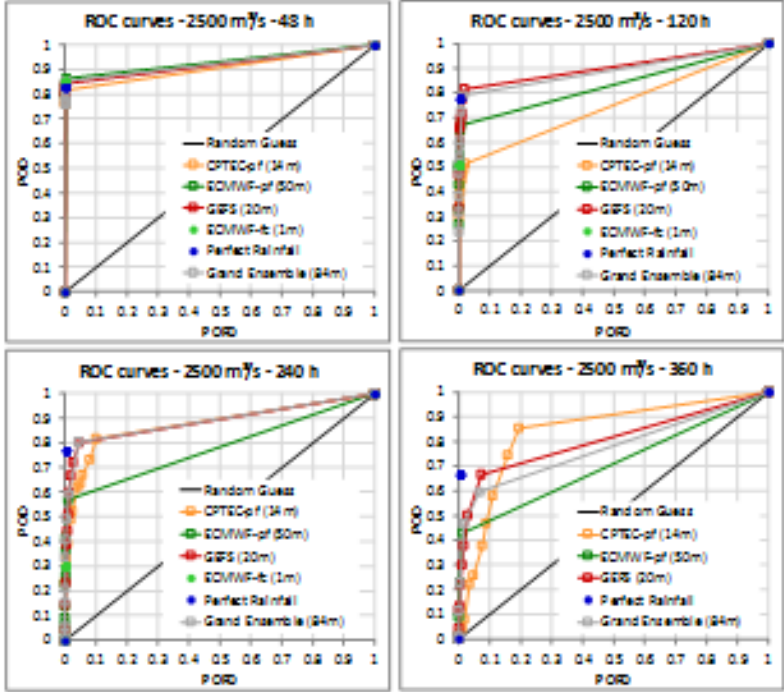

Figure 3 ROC curves considering the $2500 \mathrm{~m}^{3} / \mathrm{s}$ flow threshold.
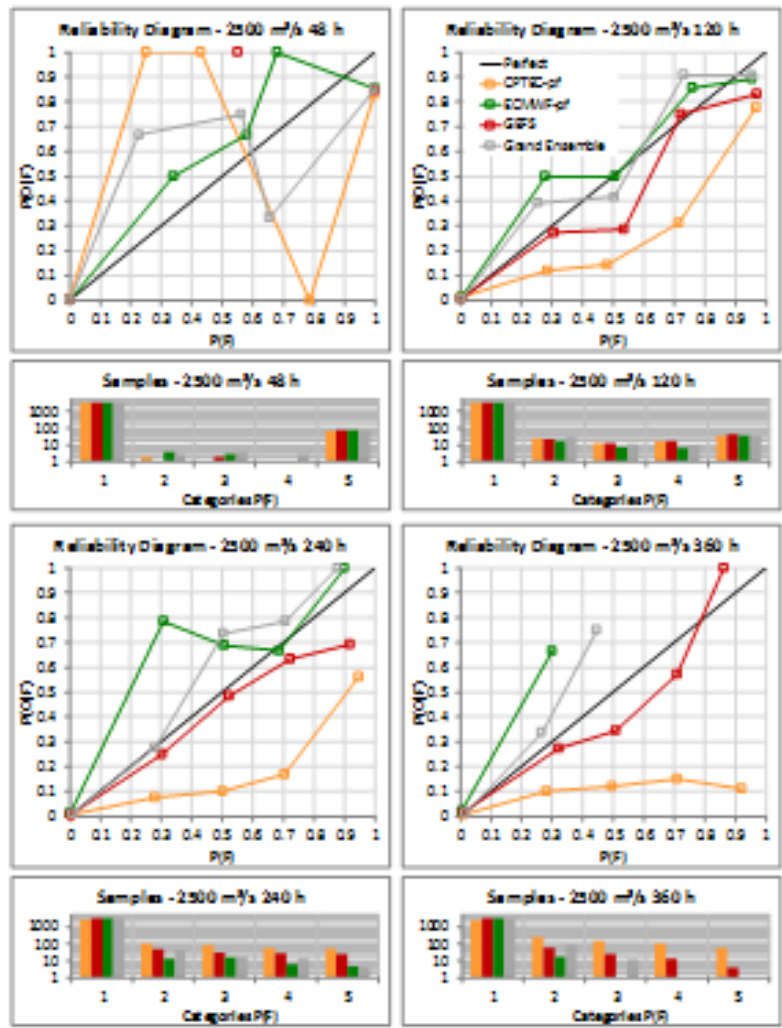

Figure 4 Reliability diagrams considering the $2500 \mathrm{~m}^{3} / \mathrm{s}$ flow threshold.

\section{Conclusion}

The main conclusions of this research are that there is an added value of ensembles scenarios dependent on the EPS used to run the hydrological forecasting system regarding the sediment management decision making for Aimorés HPP. Furthermore, the use of the Grand Ensemble seems to be a good strategy in terms of performance and robustness. The assessments results also give more credibility to 
CEMIG in the realization and communication of pass-through or flushing operation with the stakeholders involved.

\section{Acknowledgements}

The author would like to acknowledge the institutions CAPES (Coordenação de Aperfeiçoamento de Pessoal de Nivel Superior) and $\mathrm{CNPq}$ (Conselho Nacional de Desenvolvimento Cientifico e Tecnológico) for research support.

\section{Conflict of interest}

There are no financial conflicts or conflict of interest in carrying out this research.

\section{References}

1. Cuo L, Pagano TC, Wang QJ. A review of quantitative precipitation forecasts and their use in short- to medium-range streamflow forecasting. Journal of Hydrometeorology. 2011;12:713-728.

2. Fan FM, Schwanenberg D, Collischonn W, et al. Verification of inflow into hydropower reservoirs using ensemble forecasts of the TIGGE database for large scale basins in Brazil. Journal of Hydrology: Regional Studies. 2015;4(B):196-227.
3. Collischonn W, Allasia DG, Silva BC, et al. The MGB-IPH model for large scale rainfall-runoff modeling. Hydrological Sciences Journal. 2007;52(5):878-895.

4. Pontes PRM, Fan FM, Fleischmann AS, et al. Mgb-Iph model for hydrological and hydraulic simulation of large floodplain river systems coupled with open source GIS. Environmental Modelling \& Software. 2017;94:1-20.

5. Werner M, Schellekens J, Gijsbers P, et al. The Delft-FEWS Flow Forecasting System. Environmental Modelling \& Software. 2013;40:65-77.

6. Bougeault $\mathrm{P}$, Toth $\mathrm{Z}$, Bishop $\mathrm{C}$, et al. The Thorpex Interactive Grand Global Ensemble (Tigge). Bull Amer Met Soc. 2010;91:1059-1072.

7. Brown JD, Demargne J, Seo DJ, et al. The ensemble verification system (EVS): a software tool for verifying ensemble forecasts of hydrometeorological and hydrologic variables at discrete locations. Environmental Modelling \& Software. 2010;25(7):854-872. 